\title{
Synthesis of $\mathrm{Mo}_{2} \mathrm{C}$ and $\mathrm{W}_{2} \mathrm{C}$
} Nanoparticle Electrocatalysts for the Efficient Hydrogen Evolution Reaction in Alkali and Acid Electrolytes

\author{
Sajjad Hussain ${ }^{1,2}$, Dhanasekaran Vikraman ${ }^{3}$, Asad Feroze ${ }^{1,4}$, Wooseok Song ${ }^{5}$, \\ Ki-Seok An ${ }^{5}$, Hyun-Seok Kim ${ }^{3}$, Seung-Hyun Chun ${ }^{1,4}$ and Jongwan Jung ${ }^{1,2 *}$ \\ ${ }^{1}$ Graphene Research Institute, Sejong University, Seoul, South Korea, ${ }^{2}$ Department of Nano and Advanced Materials \\ Engineering, Sejong University, Seoul, South Korea, ${ }^{3}$ Division of Electronics and Electrical Engineering, Dongguk \\ University-Seoul, Seoul, South Korea, ${ }^{4}$ Department of Physics, Sejong University, Seoul, South Korea, ${ }^{5}$ Thin Film Materials \\ Research Center, Korea Research Institute of Chemical Technology, Daejeon, South Korea
}

OPEN ACCESS

Edited by:

Yao Zheng,

University of Adelaide, Australia

Reviewed by:

Bao Yu Xia

Huazhong University of Science and Technology, China

Shichun Mu,

Wuhan University of

Technology, China

*Correspondence:

Jongwan Jung

jwjung@sejong.ac.kr

Specialty section: This article was submitted to

Electrochemistry,

a section of the journal

Frontiers in Chemistry

Received: 14 August 2019 Accepted: 10 October 2019

Published: 25 October 2019

Citation:

Hussain S, Vikraman D, Feroze A, Song W, An K-S, Kim H-S, Chun S-H and Jung $J$ (2019) Synthesis of $\mathrm{MO}_{2} \mathrm{C}$ and $\mathrm{W}_{2} \mathrm{C}$ Nanoparticle

Electrocatalysts for the Efficient Hydrogen Evolution Reaction in Alkali and Acid Electrolytes.

Front. Chem. 7:716

doi: 10.3389/fchem.2019.00716
The synthesis of low cost, high efficacy, and durable hydrogen evolution electrocatalysts from the non-noble metal group is a major challenge. Herein, we establish a simple and inexpensive chemical reduction method for producing molybdenum carbide $\left(\mathrm{Mo}_{2} \mathrm{C}\right)$ and tungsten carbide $\left(\mathrm{W}_{2} \mathrm{C}\right)$ nanoparticles that are efficient electrocatalysts in alkali and acid electrolytes for hydrogen evolution reactions ( $\mathrm{HER}$ ). $\mathrm{Mo}_{2} \mathrm{C}$ exhibits outstanding electrocatalytic behavior with an overpotential of $-134 \mathrm{mV}$ in acid medium and of $-116 \mathrm{mV}$ in alkaline medium, while $\mathrm{W}_{2} \mathrm{C}$ nanoparticles require an overpotential of $-173 \mathrm{mV}$ in acidic medium and $-130 \mathrm{mV}$ in alkaline medium to attain a current density of $10 \mathrm{~mA} \mathrm{~cm}-2$. The observed results prove the capability of high- and low-pH active electrocatalysts of $\mathrm{Mo}_{2} \mathrm{C}$ and $\mathrm{W}_{2} \mathrm{C}$ nanoparticles to be efficient systems for hydrogen production through HER water electrolysis.

Keywords: $\mathrm{Mo}_{2} \mathrm{C}, \mathrm{W}_{2} \mathrm{C}$, nanoparticle, $\mathrm{HER}$, electrocatalyst

\section{INTRODUCTION}

A direct and effective route to clean and renewable hydrogen $\left(\mathrm{H}_{2}\right)$ production by water splitting requires a robust catalyst to ensure sustainable efficiency (Vikraman et al., 2017). Platinum (Pt)based systems are recognized as highly energetic HER catalysts that boast various $\mathrm{pH}$ tolerances and almost zero overpotential, but their high cost, originating from the scarcity of platinum, severely hinders their extensive use (Jacobsson et al., 2013; Peng et al., 2014). To reduce the use of Pt, intensive research has been conducted to prepare low-cost, highly active, and electrochemically stable HER electrocatalysts comprised of abundant elements as an alternative (Vikraman et al., 2018; Hussain et al., 2019a). Numerous types of non-scarce transition metal compounds, such as layered transition metal dichalcogenides (LTMDs) (Laursen et al., 2012; Seok et al., 2017; Hussain et al., 2018), phosphides (Lv and Wang, 2017; Pei et al., 2018), transition metal carbides (TMC) (Huang et al., 2016; Shi et al., 2017), and their composites (Ren et al., 2018; Vikraman et al., 2019b) have been shown to produce excellent HER activities because of their unique electronic structures. Various molybdenum selenide $\left(\mathrm{MoSe}_{2}\right)$-based materials, in particular, have been reported as being 
suited for replacing Pt in HER electrocatalysts (Ren et al., 2018; Hussain et al., 2019a; Vikraman et al., 2019a). In addition, attaching $\mathrm{Mo}_{2} \mathrm{C}$ and $\mathrm{W}_{2} \mathrm{C}$ to a carbon matrix has been shown to produce high-rate charge transfer properties during HER and to alleviate surface aggregation (Pan et al., 2014; Youn et al., 2014; Wu et al., 2016). Previous reports suggested that the HER electrocatalytic performance of $\mathrm{Mo}_{2} \mathrm{C}$ - and $\mathrm{W}_{2} \mathrm{C}$-based catalysts mainly results from the morphology (Ang et al., 2016; Ishii et al., 2016; Peng et al., 2017), crystalline phases (Wan et al., 2014; Lin et al., 2017), and composition (Yu et al., 2018; Zhang et al., 2018) of the catalysts and the synthetic protocol. However, the critical challenge is to design and develop carbide-based catalysts with comparable catalytic performance to Pt for practical applications. Until now, carbide-based materials have shown inferior catalytic properties due to their poor activities (Wu et al., 2016; Yu et al., 2018; Zhang et al., 2018). An earlier study reported the HER behavior of commercially available $\mathrm{Mo}_{2} \mathrm{C}$ meshes in both basic and acidic solutions, showing a comparatively high overpotential of $-190 \sim-230 \mathrm{mV}$ at a cathodic current of $10 \mathrm{mAcm}^{-2}$ (Vrubel and $\mathrm{Hu}, 2012)$. Performance has since been upgraded by tuning its nanocrystal size (Ma R. et al., 2015; Chen et al., 2016). Hence, $\mathrm{Mo}_{2} \mathrm{C}$ and $\mathrm{W}_{2} \mathrm{C}$ nanoparticles with high catalytic activity and robustness remain open for future research.

Various methods have been employed to prepare TMCbased catalysts (Wu et al., 2016; Zhu et al., 2016; An and Xu, 2019). Gong et al. obtained $\mathrm{WC}_{\mathrm{x}} / \mathrm{MoC}_{\mathrm{x}}$-based electrocatalysts by carbonizing $\mathrm{W} / \mathrm{WO}_{3}$ or $\mathrm{Mo} / \mathrm{MoO}_{3}$ under the flow of carbon precursors $\left(\mathrm{C}_{2} \mathrm{H}_{6}, \mathrm{CH}_{4}\right.$, or $\mathrm{CO}$, and $\left.\mathrm{H}_{2}\right)$, but very low surface areas were obtained (Gong et al., 2016). Tantalum carbide nanocrystals have been prepared via a refined $\mathrm{Cl}_{2}$ assisted "micro-cutting-fragmentation" approach and produced an overpotential of -146 mV@10 mA cm ${ }^{-2}$ for HER (Kou et al., 2017). Different methodologies have been used to prepare $\mathrm{Mo}_{2} \mathrm{C}$ and its hybrids for HER applications (Pu et al., 2016; Kou et al., 2018; Liang et al., 2019). Tungsten carbides can exist in different phases, such as $\mathrm{WC}$, metastable $\mathrm{W}_{2} \mathrm{C}$, and $\mathrm{WC}_{1-\mathrm{x}}$, but during the last decade, most researchers have exclusively focused on the WC phase instead of the $\mathrm{W}_{2} \mathrm{C}$ phase (Neylon et al., 1999; Ishii et al., 2016). W/WC synthesized by Kou et al. (2019) showed an overpotential of $159 \mathrm{mV} @ 10 \mathrm{~mA} \mathrm{~cm}^{-2}$. As per experimental and theoretical calculations, the $\mathrm{W}_{2} \mathrm{C}$ phase exhibits more HER active catalytic properties than does WC, with a low negative Gibbs free energy $(\Delta \mathrm{GH})$ for hydrogen adsorption and high Fermi level electronic density of states (DOS) (Colton et al., 1975; Gong et al., 2016). $\beta$-phase $\mathrm{Mo}_{2} \mathrm{C}$ and the $\mathrm{W}_{2} \mathrm{C}$ phase, in particular, have been validated as effective HER electrocatalysts despite their bulky natures, and their activity could be further increased by engineering with appropriate nanosize structures (Huang et al., 2016).

Herein, we have successfully synthesized $\mathrm{Mo}_{2} \mathrm{C}$ and $\mathrm{W}_{2} \mathrm{C}$ nanoparticles for HER application via a simple and economical chemical reduction method. The electrochemical results indicate that $\mathrm{Mo}_{2} \mathrm{C}$ nanoparticles exhibit superior HER electrocatalytic behavior over $\mathrm{W}_{2} \mathrm{C}$ in both alkaline and acid solutions, with small Tafel slopes and distinct solidity. We believe that our present investigation provides effective strategies for designing and preparing the new nanostructured TMC-based HER catalysts.

\section{RESULTS AND DISCUSSION}

The chemically reduced synthesis scheme and the atomic structures of the $\mathrm{Mo}_{2} \mathrm{C}$ and $\mathrm{W}_{2} \mathrm{C}$ nanoparticles are pictorially represented in Figure 1. Raman characterization was performed for structural confirmation of commercial and chemically reduced $\mathrm{Mo}_{2} \mathrm{C}$ and $\mathrm{W}_{2} \mathrm{C}$ nanoparticles. Figure $2 \mathrm{~A}$ shows the Raman spectra of commercial $\mathrm{Mo}_{2} \mathrm{C}$ and $\mathrm{W}_{2} \mathrm{C}$ and chemically reduced $\mathrm{Mo}_{2} \mathrm{C}$ and $\mathrm{W}_{2} \mathrm{C}$. The commercial $\mathrm{Mo}_{2} \mathrm{C}$ revealed unclear peaks, whereas the chemically reduced $\mathrm{Mo}_{2} \mathrm{C}$ produced distinctive peaks at 661,818 , and $990 \mathrm{~cm}^{-1}$, credited to $\beta-\mathrm{Mo}_{2} \mathrm{C}$ (Hussain et al., 2019b). In addition, the $\mathrm{G}$ band was positioned at $1,582 \mathrm{~cm}^{-1}$ and the $\mathrm{D}$ band was positioned at $1,349 \mathrm{~cm}^{-1}$, which corresponds to the $\mathrm{sp}^{2-}$ bonded carbon atoms and disarranged graphite carbon, respectively (Ma F. et al., 2015). The intensity ratio of the D-band to the $\mathrm{G}$-band (i.e., $\mathrm{I}_{\mathrm{D}} / \mathrm{I}_{\mathrm{G}}$ ) is 0.85 for $\mathrm{Mo}_{2} \mathrm{C}$, comparable to long-time carbonized graphene layers with high conductivity, which may facilitate charge transfer during HER (Li et al., 2016; Lv et al., 2017; Wang et al., 2017). For commercial and chemically reduced $\mathrm{W}_{2} \mathrm{C}$, the strong peaks observed at 693 and $807 \mathrm{~cm}^{-1}$ originate from the stretching vibration of $\mathrm{W}-\mathrm{C}$ (Yan et al., 2017). The D and G bands were exhibited at 1,351 and $1,583 \mathrm{~cm}^{-1}$ for the chemically reduced $\mathrm{W}_{2} \mathrm{C}$ (Yan et al., 2017; Zhang et al., 2018). The observed results are in good agreement with previous reports (Yan et al., 2017; Hussain et al., 2019a).

$\mathrm{X}$-ray diffraction (XRD) was investigated to reveal the material structure of the commercial and chemical $\mathrm{Mo}_{2} \mathrm{C}$ and $\mathrm{W}_{2} \mathrm{C}$ nanoparticles (Figure 2B). For $\mathrm{Mo}_{2} \mathrm{C}$, the XRD patterns revealed reflections at $34.5,38.1,39.5,52.3,61.7,69.6,74.7$, and $75.7^{\circ}$, which were indexed to the (100), (002), (101), (102), (110), (103), (112), and (201) planes of $\beta-\mathrm{Mo}_{2} \mathrm{C}$ (JCPDS: 35-0787), which is the most active phase of $\mathrm{Mo}_{2} \mathrm{C}$ for HER. In the case of $\mathrm{W}_{2} \mathrm{C}$, the XRD patterns produced peaks at $31.5,35.1,48.8,64.1$, $65.8,73.2,75.6$, and $77.1^{\circ}$ due to the (020), (002), (220), (041), (123), (004), (142), and (322) lattice planes, respectively (JCPDS: 89-2371). Compared with commercial samples, the chemically reduced samples showed higher-intensity peaks, which can be attributed to the enriched crystallinity in the nanoparticles compared to in bulk (Hussain et al., 2019a). No discernible peaks in either the $\mathrm{Mo}_{2} \mathrm{C}$ or $\mathrm{W}_{2} \mathrm{C}$ samples could be assigned to $\mathrm{Mo} / \mathrm{W}$, carbide, or other Mo/W non-stoichiometric phases and impurities, indicating the capability of the synthetic method to prepare effective nanostructures from bulk.

Morphology and microstructure modifications were inspected using field emission scanning electron microscopy (FESEM) and transmission electron microscopy (TEM). Figures 3a-c show FESEM images for reduced $\mathrm{Mo}_{2} \mathrm{C}$ nanoparticles. The observed images clearly indicated that larger sized grains were constructed through the accumulation of spherically shaped nanoparticles. The composition of reduced $\mathrm{Mo}_{2} \mathrm{C}$ nanoparticles was examined by energy dispersive spectroscopy (EDS), as shown in Figure S1. The observed composition of the chemically reduced sample is in good agreement with the claim of $\mathrm{Mo}_{2} \mathrm{C}$ formation, and EDS mapping images for the nanoparticles are provided in Figure S2. TEM images at different magnifications of $\mathrm{Mo}_{2} \mathrm{C}$ nanoparticles are provided in Figures 3d-g. The large grains are clearly seen in the lower-magnification TEM image (Figure 3d), and the typical 
A

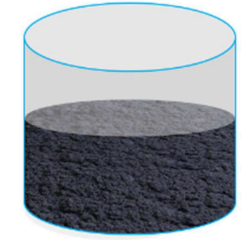

Stirring - $3 \mathrm{~h}$ @

Room temperature

Ethanol

Commercial $\mathrm{W}_{2} \mathrm{C}$ or $\mathrm{Mo}_{2} \mathrm{C}$

B

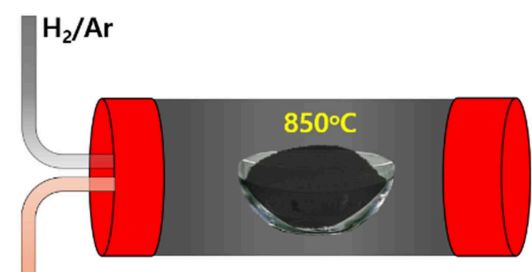

$\mathrm{CH}_{4}$

Rapid annealing

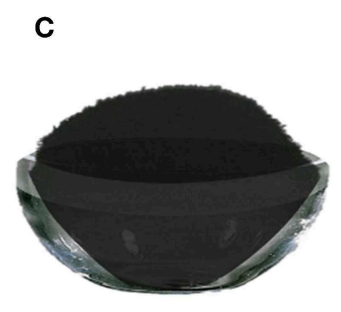

$\mathrm{W}_{2} \mathrm{C}$ or $\mathrm{Mo}_{2} \mathrm{C}$ nanoparticles
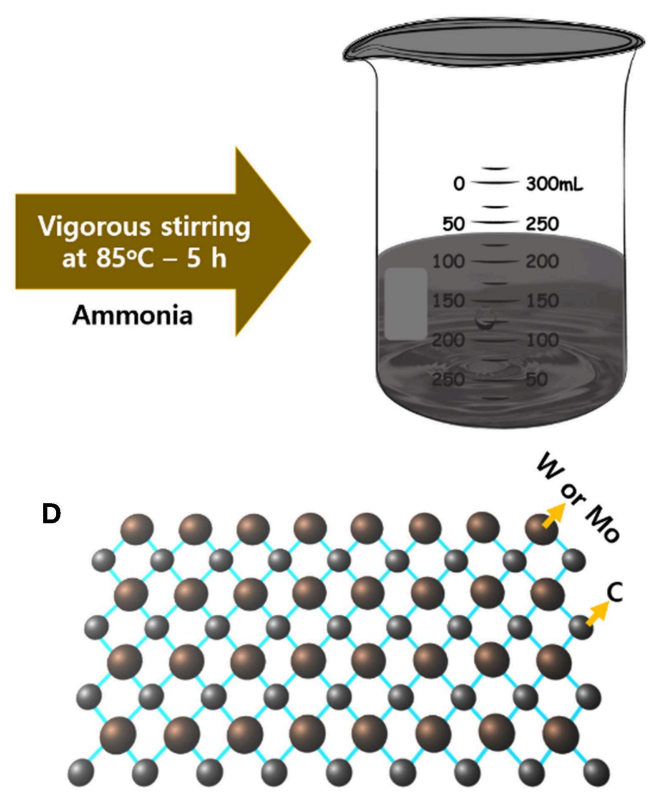

TMC atomic structure

FIGURE 1 | Schematic representation of the (A) chemically reduction, (B) thermal annealing at $850^{\circ} \mathrm{C}$, (C) prepared powders, and (D) atomic structure of $\mathrm{Mo}_{2} \mathrm{C}$ and $\mathrm{W}_{2} \mathrm{C}$ nanoparticles.
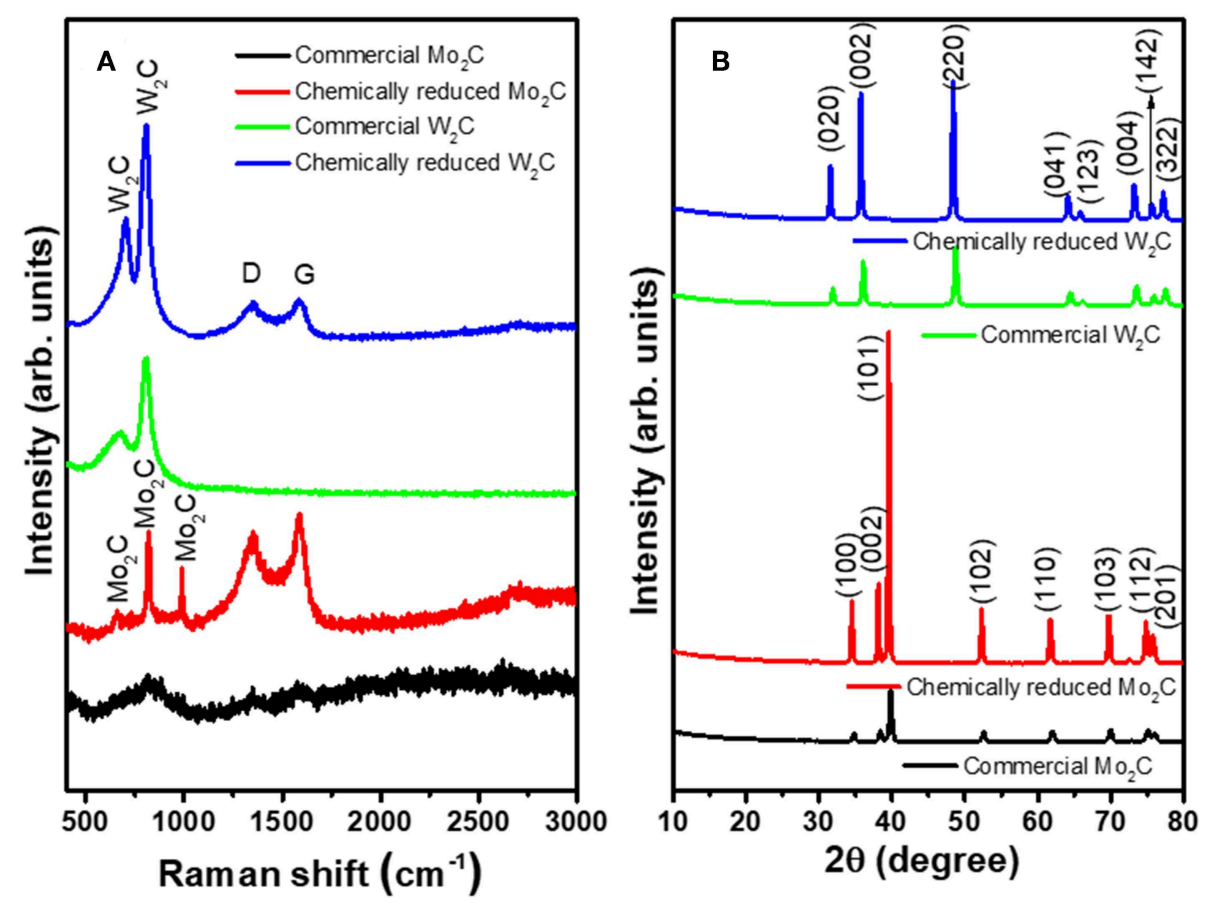

FIGURE 2 | (A) XRD patterns and (B) Raman spectra of commercial $\mathrm{Mo}_{2} \mathrm{C}$ and $\mathrm{W}_{2} \mathrm{C}$ and chemically reduced $\mathrm{Mo}_{2} \mathrm{C}$ and $\mathrm{W}_{2} \mathrm{C}$.

2D layered structures are shown in the higher-magnification images. A high-resolution TEM image showing a fingerprintlike structure is shown in Figure 3g, and its fast Fourier transform (FFT) and inverse FFTs are inserted. The intensity profile extracted proved the existence of (101) lattice plane spacing $(0.228 \mathrm{~nm})$ between the fringes, as shown in Figure $\mathbf{3 h}$. 

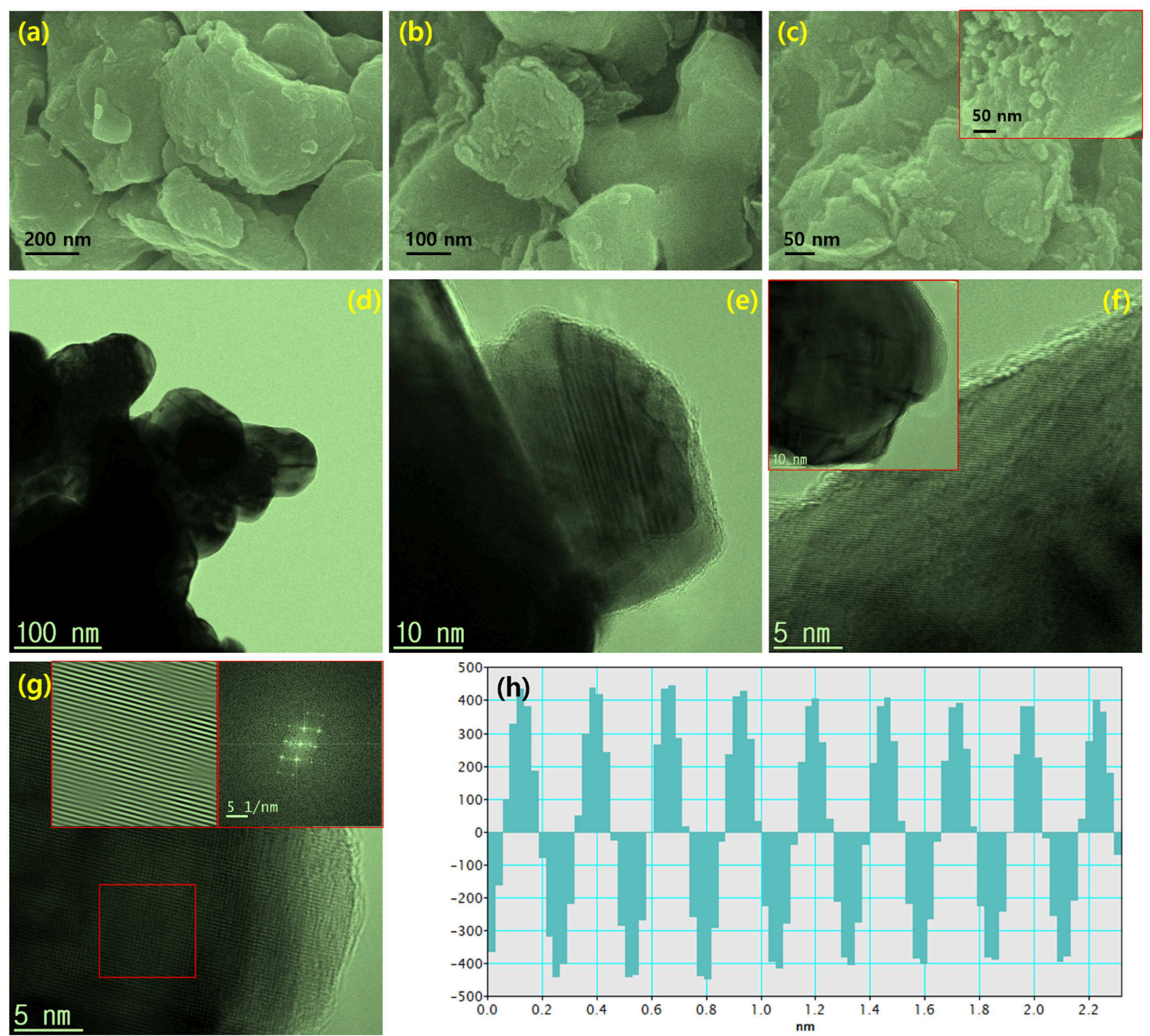

FIGURE 3 | (a-c) FESEM images at different magnifications for chemically reduced $\mathrm{Mo}_{2} \mathrm{C}$ nanoparticles, (d-h) TEM micrographs of Mo $2 \mathrm{C}$ nanoparticles, (d-f) Different magnifications of TEM images of dispersed nanosheet structures, (g) High-resolution TEM image with the typical fingerprint-type layered structure, with insets of FFT and inverse FFT patterns obtained via point mask mode, and (h) intensity profile.

Hence, the microscopic images clearly proved the formation of $\mathrm{Mo}_{2} \mathrm{C}$ nanoparticles.

Figure 4 shows FESEM and TEM images of chemically reduced $\mathrm{W}_{2} \mathrm{C}$ nanoparticles. The nanoparticles consist of inhomogeneous grains (Figures $4 \mathbf{a}-\mathbf{c}$ ). The EDS spectrum confirmed the existence of $\mathrm{W}_{2} \mathrm{C}$ nanoparticles (Figure S3), and their mapping images further supported the claim of $\mathrm{W}_{2} \mathrm{C}$ nanoparticle formation (Figure S4). The TEM images provided valuable insights regarding the $\mathrm{W}_{2} \mathrm{C}$ nanoparticles (Figures $4 \mathbf{d}-\mathbf{g}$ ). The irregularly sized nanograins were clearly seen in the low- and highermagnification TEM images (Figures 4f,g). The FFT image showed the (002) $\mathrm{W}_{2} \mathrm{C}$ plane $(0.26 \mathrm{~nm}$ spacing) (Figure 4h). The observed results are well-correlated with the $\mathrm{XRD}$ results.

An X-ray photoelectron spectroscopy (XPS) study was conducted to validate the composition of reduced $\mathrm{Mo}_{2} \mathrm{C}$ and
$\mathrm{W}_{2} \mathrm{C}$. The XPS survey spectra revealed the occurrence of $\mathrm{Mo}_{2} \mathrm{C}$ (C and Mo)- and $\mathrm{W}_{2} \mathrm{C}(\mathrm{C}$ and $\mathrm{W})$-based elements, as shown in Figures S5A,B. Figure 5A shows the de-convoluted highresolution region for Mo $3 \mathrm{~d}$, with the Mo $3 \mathrm{~d}_{5 / 2}$ and Mo $3 \mathrm{~d}_{3 / 2}$ peaks at 228.6 and $231.9 \mathrm{eV}$, which reveals the carbidic Mo phase. The peaks at 233.3 and $235.9 \mathrm{eV}$ are from molybdenum oxide $\left(\mathrm{Mo}^{6+}\right.$ ), indicating surface oxidation in an air environment (Cui et al., 2014; Tang et al., 2015; Huang et al., 2016; Fan et al., 2018; Hussain et al., 2019a). The C 1s spectrum (Figure 5B) at a $284.8 \mathrm{eV}$ binding energy is characteristic of the $\mathrm{sp}^{2}$ carbon relation in $\mathrm{Mo}_{2} \mathrm{C}$, whereas a satellite peak emerges at $288.8 \mathrm{eV}$ due to $\mathrm{C}-\mathrm{O}$ bonding ( $\mathrm{Wu}$ et al., 2016). Figure 5C shows the high-resolution W 4f XPS spectrum from chemically reduced $\mathrm{W}_{2} \mathrm{C}$. The deconvoluted peaks revealed at 31.64 and $33.81 \mathrm{eV}$ were credited to $4 f_{7 / 2}$ and $4 f_{5 / 2}$, respectively, for the $W 4 f$ atom. The high-resolution $\mathrm{C} 1 \mathrm{~s}$ spectrum (Figure 5D) of $\mathrm{W}_{2} \mathrm{C}$ exposed the $\mathrm{sp}^{2}$ graphitic carbon peak at $283.02 \mathrm{eV}$ and $\mathrm{C}=\mathrm{O}$ 

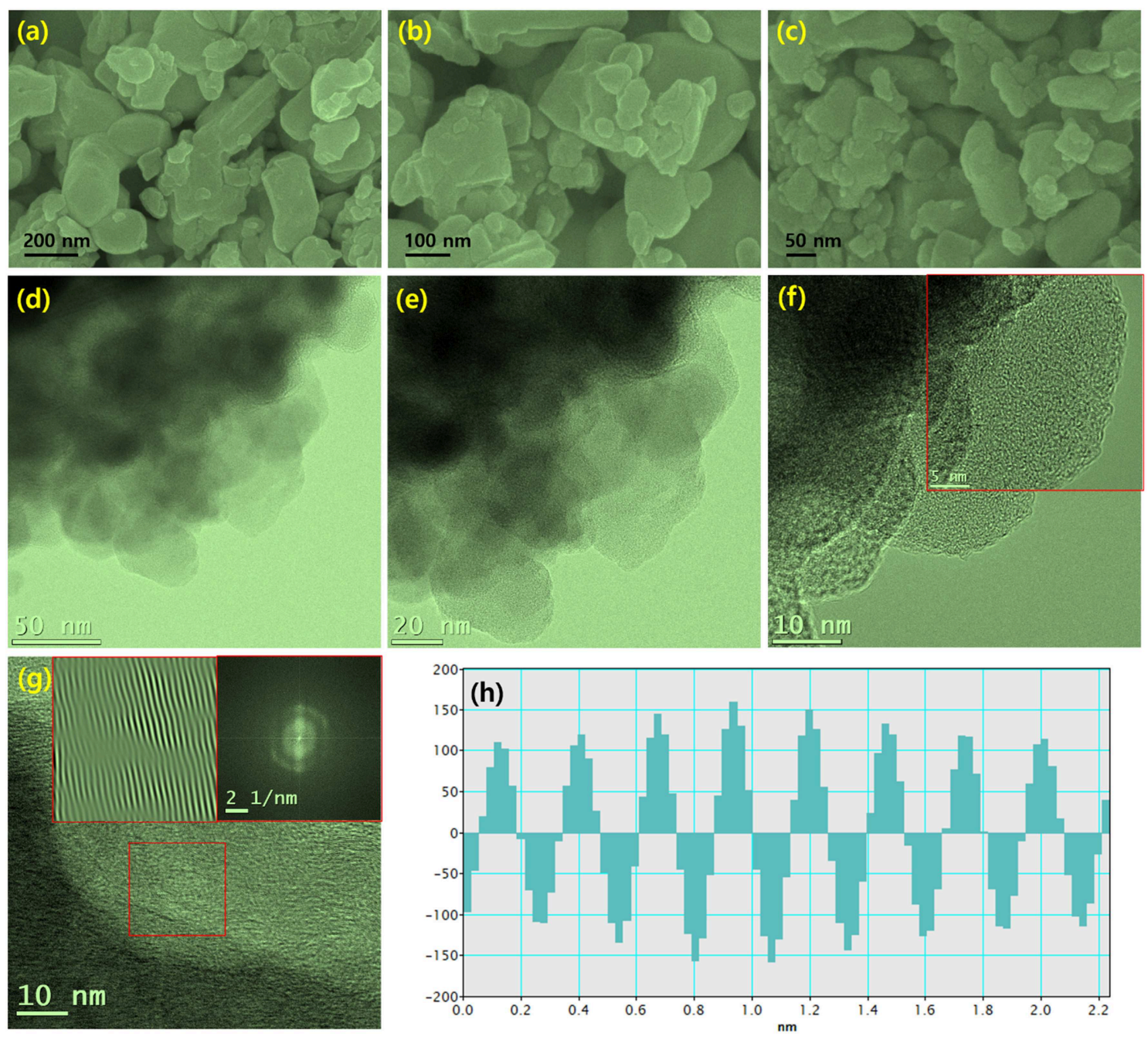

FIGURE 4 | (a-c) FESEM images of different magnification for chemically reduced $\mathbf{W}_{2} \mathrm{C}$ nanoparticles, (d-h) TEM micrographs of W $\mathrm{W}_{2} \mathrm{C}$ nanoparticles (d-e) Different magnifications of TEM images of accumulated nanosheet structures, $(\mathbf{f}, \mathbf{g})$ high-resolution TEM images of interconnected layers with a fingerprint structure, with an inset showing the inverse FFT pattern obtained via point mask mode, and (h) intensity profile.

peak at $285.1 \mathrm{eV}$ (Berglund et al., 2014; Ko et al., 2017). The observed results confirmed the formation of $\mathrm{Mo}_{2} \mathrm{C}$ and $\mathrm{W}_{2} \mathrm{C}$, which is in good agreement with the earlier literature (Ma F. et al., 2015; Yan et al., 2017). The surface area modifications were measured by the nitrogen $\left(\mathrm{N}_{2}\right)$ adsorption/desorption isotherms for chemically reduced $\mathrm{Mo}_{2} \mathrm{C}$ and $\mathrm{W}_{2} \mathrm{C}$ nanoparticles via the Brunauer Emmett Teller (BET) method (Figures S6A,B). Surface area of 0.91 and $1.75 \mathrm{~m}^{2} \cdot \mathrm{g}^{-1}$ were observed for the chemically reduced $\mathrm{Mo}_{2} \mathrm{C}$ and $\mathrm{W}_{2} \mathrm{C}$, respectively, compared with the reported values of their commercial samples (Gao et al., 2014; Hussain et al., 2019a). In addition, the pore diameter vs. pore volume profile (Figure S6B) shows the mesoporous nature of chemically reduced $\mathrm{Mo}_{2} \mathrm{C}$ and $\mathrm{W}_{2} \mathrm{C}$, with pore diameters of 14.9 and $21.4 \mathrm{~nm}$ and pore volumes of 0.003 and 0.009 $\mathrm{cm}^{3} \cdot \mathrm{g}^{-1}$, respectively.

The HER electrocatalytic activities of $\mathrm{Mo}_{2} \mathrm{C}$ - and $\mathrm{W}_{2} \mathrm{C}$-coated nickel foam (NF) electrodes were analyzed by linear sweep voltammogram (LSV) in $1 \mathrm{M} \mathrm{KOH}$ and $0.5 \mathrm{M} \mathrm{H}_{2} \mathrm{SO}_{4}$ electrolyte solutions (scan rate of $10 \mathrm{mV} \mathrm{s}^{-1}$, three-electrode setup). For the evaluation, a commercial $\mathrm{Pt} / \mathrm{C}$ was used as an electrode, and the results were as follows. Figure $6 \mathbf{A}$ shows the LSV curves of commercial $\mathrm{Pt} / \mathrm{C}$ and reduced $\mathrm{Mo}_{2} \mathrm{C}$ and $\mathrm{W}_{2} \mathrm{C}$ catalysts in a $0.5 \mathrm{M} \mathrm{H}_{2} \mathrm{SO}_{4}$ solution. As anticipated, the commercial $\mathrm{Pt} / \mathrm{C}$ catalyst showed the highest HER activity, which had an overpotential of $\sim-49 \mathrm{mV}$. For bare $\mathrm{NF}, \mathrm{Mo}_{2} \mathrm{C}$, and $\mathrm{W}_{2} \mathrm{C}$, overpotentials of $-423,-134$, and $-170 \mathrm{mV}$ were needed to achieve $10 \mathrm{mAcm}^{-2}$ in acidic electrolyte, respectively, lower than those of the commercial samples (Vrubel and $\mathrm{Hu}$, 2012; Chen et al., 2013). The overpotentials of the chemically reduced $\mathrm{Mo}_{2} \mathrm{C}$ and $\mathrm{W}_{2} \mathrm{C}$ were much closer to the recently reported values for carbide-based materials in acid medium, such as $\mathrm{Mo}_{2} \mathrm{C}$ encapsulated by nitrogen and phosphorus

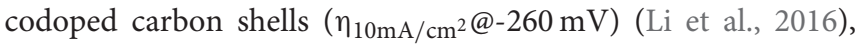
$\mathrm{Mo}_{2} \mathrm{C}$ nanoparticles embedded in chain-like Ketjenblack

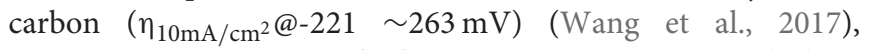

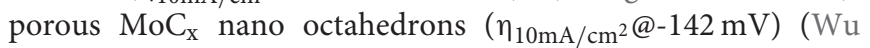



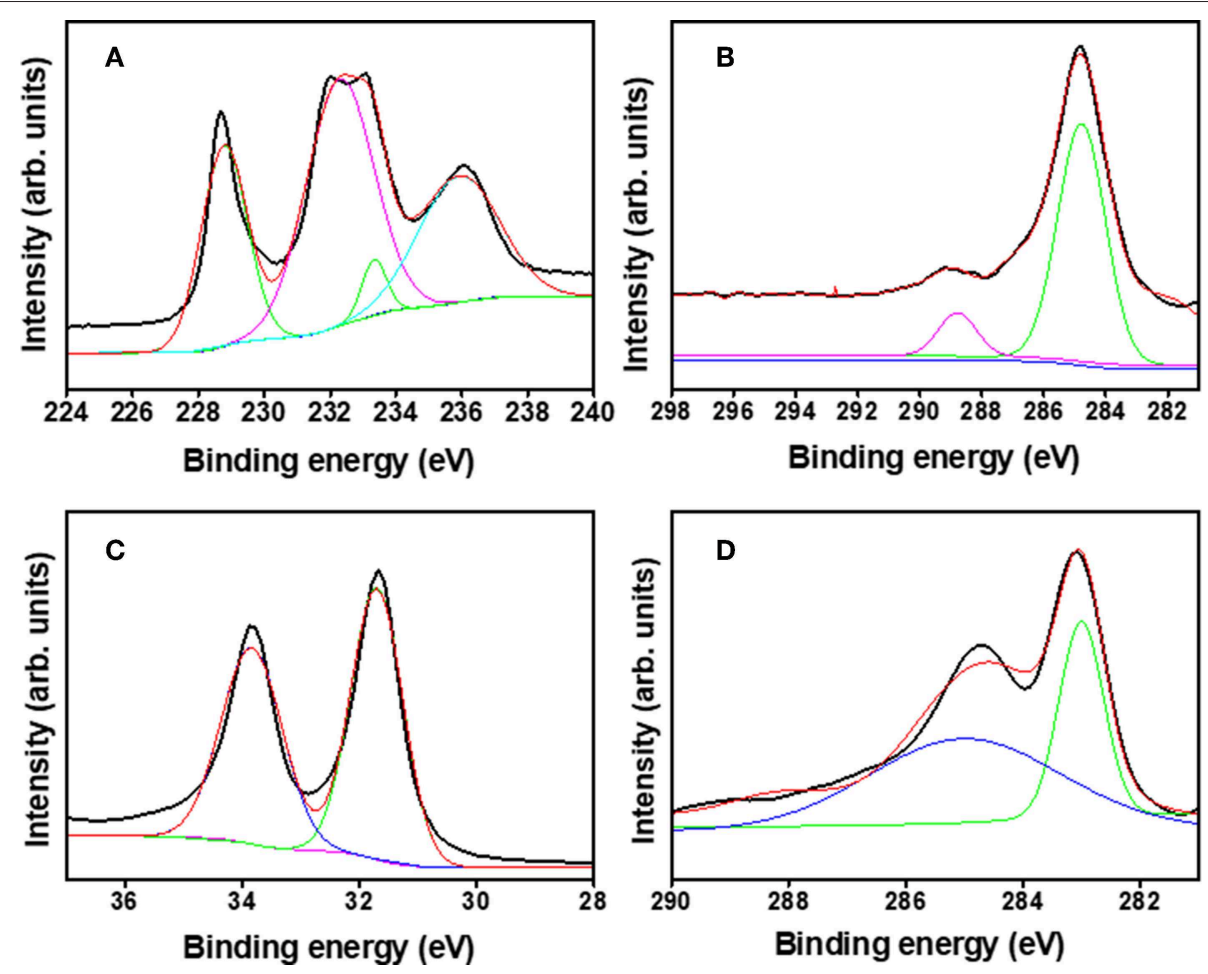

FIGURE 5 | X-ray photoemission spectra: (A) Mo 3d, (B) C 1s binding energy spectra of $\mathrm{Mo}_{2} \mathrm{C}$ nanoparticles, (C) W 4f, and (D) $\mathrm{C}$ 1s binding energy spectra of $\mathrm{W}_{2} \mathrm{C}$ nanoparticles.

et al., 2015), 3D porous scaffold-like $\mathrm{Mo}_{2} \mathrm{C} / \mathrm{C}$ nanosheet

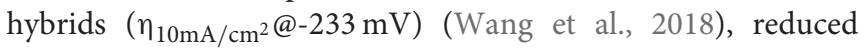
graphene oxide-based $\mathrm{Mo}_{2} \mathrm{C}$ composites $\left(\eta_{10 \mathrm{~mA} / \mathrm{cm}^{2} @-}\right.$ $206 \mathrm{mV}$ ) (Ojha et al., 2016), $\mathrm{Mo}_{2} \mathrm{C}$ nanoparticle-decorated

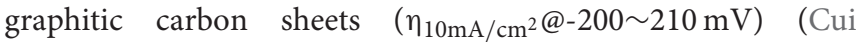
et al., 2014), $\mathrm{Mo}_{2} \mathrm{C}$ particles embedded in a sulfur and nitrogen codoped mesoporous carbon matrix $\left(\eta_{10 \mathrm{~mA} / \mathrm{cm}^{2} @-}\right.$ $146 \mathrm{mV}$ ) (An et al., 2017), and $\mathrm{Mo}_{2} \mathrm{C}$ NCs on vertically

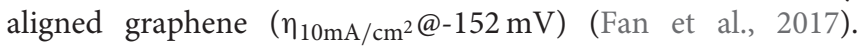
The electrocatalytic properties of $\mathrm{Pt} / \mathrm{C}, \mathrm{Mo}_{2} \mathrm{C}$, and $\mathrm{W}_{2} \mathrm{C}$ catalysts were appraised in a $1 \mathrm{M} \mathrm{KOH}$ medium (Figure 6B). Similarly, the $\mathrm{Pt} / \mathrm{C}, \mathrm{Mo}_{2} \mathrm{C}$, and $\mathrm{W}_{2} \mathrm{C}$ electrocatalysts produced $-48,-116$, and $-130 \mathrm{mV}$ overpotentials to drive the 10 $\mathrm{mAcm}^{-2}$ reaction in an alkaline electrolyte. The bare NF did not produce viable HER properties in a $1 \mathrm{M} \mathrm{KOH}$ medium. The observed results constitute a considerable advance over earlier results.

The Tafel slope signifies the characteristic activity acquired of an electrocatalyst and is derived using the Tafel equation for the HER. As shown in Figures 6C,D, Pt/C offers Tafel slopes of 43 and $48 \mathrm{mV} \cdot \mathrm{dec}^{-1}$ for acidic and alkaline electrolytes, respectively, which is comparable with the reported results (Fan et al., 2018). The extracted slope values from the Tafel plots were 83 and $86 \mathrm{mV}$ $\mathrm{dec}^{-1}$ for the acidic and 65 and $100 \mathrm{mV} \cdot \mathrm{dec}^{-1}$ for the alkali for reduced $\mathrm{Mo}_{2} \mathrm{C}$ and $\mathrm{W}_{2} \mathrm{C}$, respectively. These values indicate that the Volmer-Heyrovsky reaction step is obeyed for the whole HER process (Bockris and Potter, 1952; Yuan et al., 2018). Another important parameter, the exchange current density $\left(\mathrm{j}_{0}\right)$, was extracted to evaluate HER activity by extrapolating the linear region of the Tafel plot. A chemically reduced $\mathrm{Mo}_{2} \mathrm{C}$ catalyst displays $\mathrm{j}_{0}$ values of 0.846 and $0.131 \mathrm{~mA} \mathrm{~cm}^{-2}$ in alkali and acidic media, respectively, while a chemically reduced $\mathrm{W}_{2} \mathrm{C}$ catalyst shows $\mathrm{j}_{0}$ values of 0.438 and $0.194 \mathrm{~mA} \mathrm{~cm}^{-2}$. The observed parameters are provided in Table 1. A detailed comparison of chemically reduced $\mathrm{Mo}_{2} \mathrm{C}$ and $\mathrm{W}_{2} \mathrm{C}$ HER parameters, with the reported carbide-based materials in alkaline and acidic media, are provided in Tables S1, S2, respectively.

The observed HER properties are credited to the reduced sizes of $\mathrm{Mo}_{2} \mathrm{C}$ and $\mathrm{W}_{2} \mathrm{C}$ nanostructures and their improved morphological properties in terms of edge sites.

High electrical conductivity allows for rapid ion/electron transfer between the active electrocatalyst edge sites and also provides a high interaction area between the electrolyte and the electrode, which in turn enhances the electrochemical performance. The charge transport mechanism was clarified by employing electrochemical impedance spectroscopy (EIS) studies to understand the $\mathrm{HER}$ mechanism of $\mathrm{Mo}_{2} \mathrm{C}$ and $\mathrm{W}_{2} \mathrm{C}$ nanoparticles at the interface between electrodes and electrolytes. The charge transfer properties with resistance $\left(\mathrm{R}_{\mathrm{ct}}\right)$ are exhibited for $\mathrm{Pt} / \mathrm{C}$ in acidic and alkaline media as shown in Figures S7A,B. The lower $\mathrm{R}_{\mathrm{ct}}$ values for chemically reduced $\mathrm{Mo}_{2} \mathrm{C}$ and $\mathrm{W}_{2} \mathrm{C}$ in acidic and alkaline media confirmed that they favor rapid electron transport in $\mathrm{H}_{2}$ evolution (Figures S7A,B). 

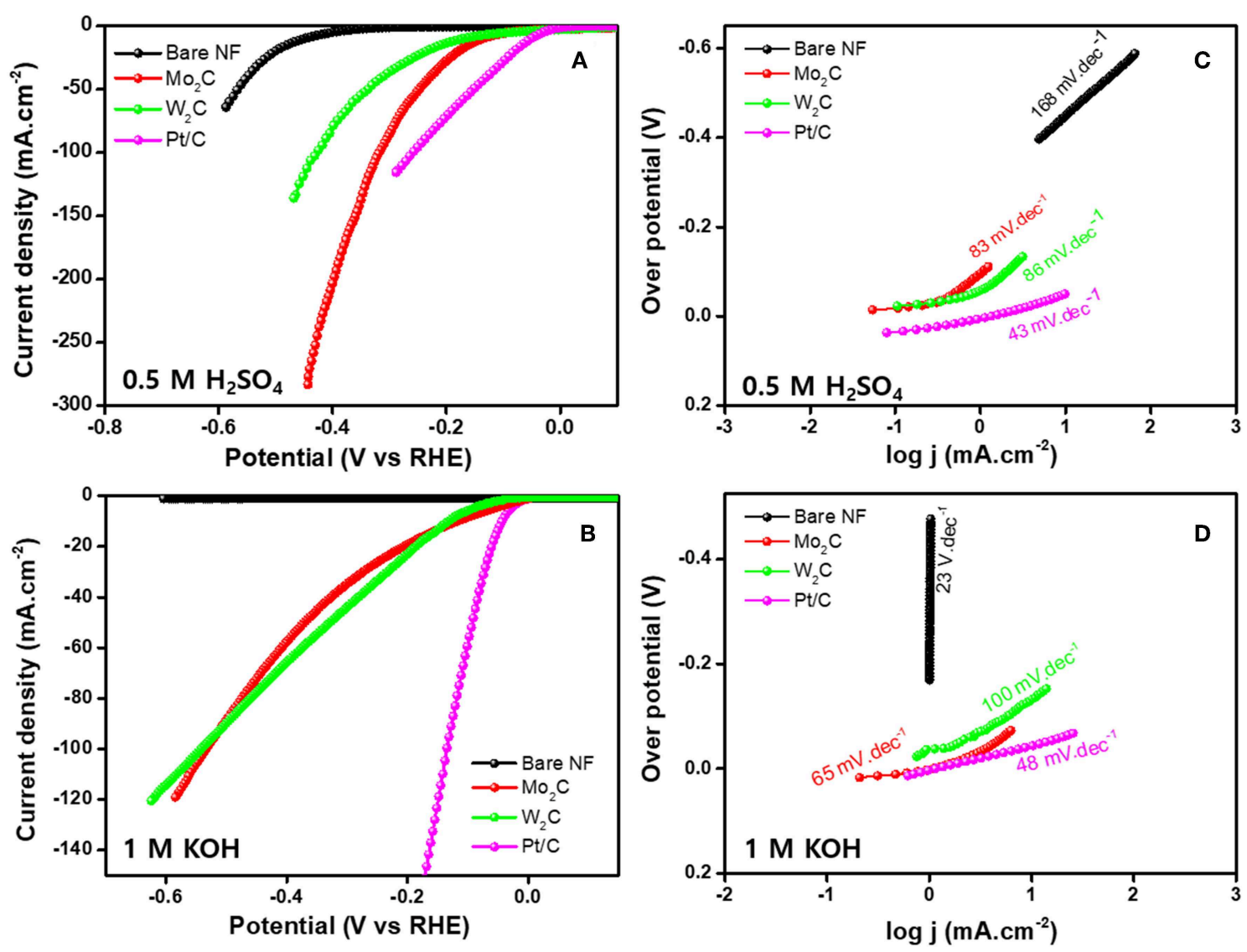

FIGURE 6 | HER performance of bare NF, Pt/C, $\mathrm{Mo}_{2} \mathrm{C}$, and $\mathrm{W}_{2} \mathrm{C}$ nanoparticle-decorated NF. (A,C) LSV profiles and their Tafel plots in $0.5 \mathrm{M} \mathrm{H} \mathrm{H}_{2} \mathrm{SO}$ and (B,D) $L S V$ profiles and their Tafel plots in $1.0 \mathrm{M} \mathrm{KOH}$.

We estimated the electrochemically active surface area (ECSA) through cyclic voltammetry $(\mathrm{CV})$, which was accomplished at different scan rates from 10 to $100 \mathrm{mVs}^{-1}$ in the non-Faradaic regions for $\mathrm{Mo}_{2} \mathrm{C}$ and $\mathrm{W}_{2} \mathrm{C}$, as shown in Figures $\mathbf{S 8 A - D}$, respectively (Zhou et al., 2016; Hussain et al., 2019a; Vikraman et al., 2019a). The double-layer capacitance $\left(\mathrm{C}_{\mathrm{dl}}\right)$ was extracted from the fitted slope value of the current differences $\left(\Delta j_{a-c}\right)$ of the cathodic and anodic peaks of $\mathrm{CV}$ profiles at $0.24 \mathrm{~V}$ vs. RHE (Figure S8E). The extracted $\mathrm{C}_{\mathrm{dl}}$ values were 2.13 and $1.42 \mathrm{mF} . \mathrm{cm}^{-2}$ in acid medium and 2.90 and $1.86 \mathrm{mF} . \mathrm{cm}^{-2}$ in alkaline medium for $\mathrm{Mo}_{2} \mathrm{C}$ and $\mathrm{W}_{2} \mathrm{C}$, respectively. The ECSA values were assessed through a previously described procedure (Vikraman et al., 2019a) and were 60.8 and $40.6 \mathrm{~cm}^{2}$ in an acidic and 72.5 and $46.5 \mathrm{~cm}^{2}$ in a alkaline medium for $\mathrm{Mo}_{2} \mathrm{C}$ and $\mathrm{W}_{2} \mathrm{C}$, respectively, indicating higher HER activity for the $\mathrm{Mo}_{2} \mathrm{C}$ system. We estimated the amount of surface active sites using the method reported by Fei et al. (2015). The turnover frequency (TOF) values of $\mathrm{Mo}_{2} \mathrm{C}$ and $\mathrm{W}_{2} \mathrm{C}$ were calculated in the acidic and alkaline media. The TOF values of $\mathrm{Mo}_{2} \mathrm{C}$ are 0.005 and $0.037 \mathrm{H}_{2} \cdot \mathrm{s}^{-1}$ at overpotentials of -134 and $-116 \mathrm{mV}$, and those of $\mathrm{W}_{2} \mathrm{C}$ are 0.015 and $0.034 \mathrm{H}_{2} \cdot \mathrm{s}^{-1}$ at overpotentials of -173 and $-130 \mathrm{mV}$ in acidic and alkaline media, respectively. The observed TOF values are comparable with
TABLE 1 | Comparison of the electrochemical parameters of different electrocatalysts.

\begin{tabular}{|c|c|c|c|c|}
\hline Electrolyte & Electrocatalysts & $\begin{array}{l}\text { Tafel slope } \\
\left(\mathrm{mV} \cdot \mathrm{dec}^{-1}\right)\end{array}$ & $\begin{array}{l}\text { Overpotential } \\
\text { (mV vs. RHE) } \\
@ 10 \mathrm{~mA} \cdot \mathrm{cm}^{-2}\end{array}$ & $\begin{array}{l}\text { Exchange } \\
\text { current } \\
\text { density (jo, } \\
\mathrm{mA} \cdot \mathrm{cm}^{-2} \text { ) }\end{array}$ \\
\hline \multirow[t]{4}{*}{$0.5 \mathrm{M} \mathrm{H}_{2} \mathrm{SO}_{4}$} & $\mathrm{Pt} / \mathrm{C}$ & 43 & -49 & 1.03 \\
\hline & $\mathrm{Mo}_{2} \mathrm{C}$ & 83 & -134 & 0.131 \\
\hline & $\mathrm{W}_{2} \mathrm{C}$ & 86 & -173 & 0.194 \\
\hline & Bare NF & 168 & -423 & 0.022 \\
\hline \multirow[t]{4}{*}{$1 \mathrm{M} \mathrm{KOH}$} & $\mathrm{Pt} / \mathrm{C}$ & 48 & -48 & 0.891 \\
\hline & $\mathrm{Mo}_{2} \mathrm{C}$ & 65 & -116 & 0.846 \\
\hline & $\mathrm{W}_{2} \mathrm{C}$ & 100 & -130 & 0.438 \\
\hline & Bare NF & - & - & - \\
\hline
\end{tabular}

previous reports (Chen et al., 2011; Fei et al., 2015; Ma L. et al., 2015; Zhang et al., 2017).

The robustness of the $\mathrm{Mo}_{2} \mathrm{C}$ and $\mathrm{W}_{2} \mathrm{C}$ catalysts was analyzed by carrying out chronoamperometric performances in $0.5 \mathrm{M}$ $\mathrm{H}_{2} \mathrm{SO}_{4}$ and in $1 \mathrm{M} \mathrm{KOH}$ for $20 \mathrm{~h}$; the results are shown in 

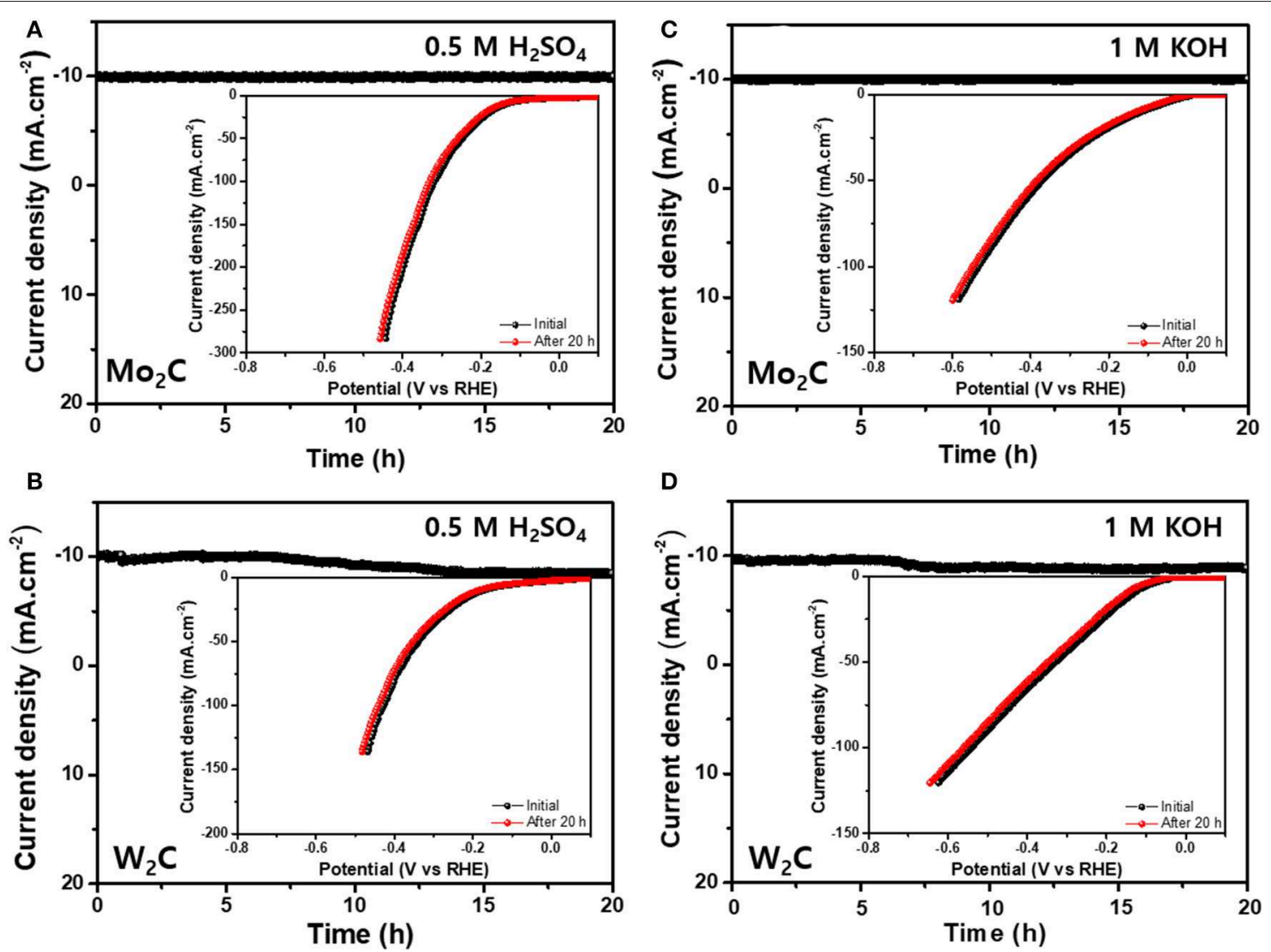

FIGURE 7 | Long-term stability tests (A,B) chronoamperometric curves for $\mathrm{Mo}_{2} \mathrm{C}$ - and $\mathrm{W}_{2} \mathrm{C}$-loaded $\mathrm{NF}$ electrocatalyst in $0.5 \mathrm{M} \mathrm{H}_{2} \mathrm{SO}_{4}$ (inset: corresponding LSV profiles for initial and after $20 \mathrm{~h}$ of $\mathrm{HER}$ performance) and (C,D) Chronoamperometric curves for $\mathrm{Mo}_{2} \mathrm{C}-$ and $\mathrm{W}_{2} \mathrm{C}-\mathrm{loaded} \mathrm{NF}$ electrocatalyst in $1.0 \mathrm{M} \mathrm{KOH}$ (inset: corresponding LSV profiles for initial and after $20 \mathrm{~h}$ of HER performance).

Figures 7A-D. The LSV profiles of $\mathrm{Mo}_{2} \mathrm{C}$ and $\mathrm{W}_{2} \mathrm{C}$ catalysts were examined after $20 \mathrm{~h}$ of HER operation $(-0.6$ to $0.15 \mathrm{~V}$ vs. RHE at a scan rate of $10 \mathrm{mV} \mathrm{s}^{-1}$ ) in alkaline and acid media (Figure 7). The polarization curves revealed the robust nature of $\mathrm{Mo}_{2} \mathrm{C}$ after $20 \mathrm{~h}$ of working operation, whereas $\mathrm{W}_{2} \mathrm{C}$ showed slight degradation. Hence, the observed deliverables established the capability of chemically reduced $\mathrm{Mo}_{2} \mathrm{C}$ catalysts with longterm durability in alkaline and acidic media, which makes them interchangeable for high-cost materials.

Furthermore, the stability of the $\mathrm{Mo}_{2} \mathrm{C}$ and $\mathrm{W}_{2} \mathrm{C}$ catalysts was investigated by XPS and FESEM analysis after continuous 20 h-HER operation in electrolytic solution (acidic medium); the results are shown in Figures S9, S10. The observed results also confirm no dramatic changes in XPS and FESEM data after continuous $20 \mathrm{~h}$ HER operation.

\section{CONCLUSIONS}

Chemically reduced $\mathrm{Mo}_{2} \mathrm{C}$ and $\mathrm{W}_{2} \mathrm{C}$ produced using an economical reduction method were successfully employed as electrocatalysts for application in HER. The observed HER results revealed that $\mathrm{Mo}_{2} \mathrm{C}$ and $\mathrm{W}_{2} \mathrm{C}$ nanoparticles had low overpotentials $\left(\eta_{-10 \mathrm{mAcm}^{-2}}=-134\right.$ and $-116 \mathrm{mV}$ and -173 and $-130 \mathrm{mV}$ for $\mathrm{Mo}_{2} \mathrm{C}$ and $\mathrm{W}_{2} \mathrm{C}$ nanoparticles, respectively) with small Tafel slopes (83 and $65 \mathrm{mV} \cdot \mathrm{dec}^{-1}$ and 86 and $100 \mathrm{mV} \cdot \mathrm{dec}^{-1}$ for $\mathrm{Mo}_{2} \mathrm{C}$ and $\mathrm{W}_{2} \mathrm{C}$ nanoparticles, respectively) in a $0.5 \mathrm{M} \mathrm{H}_{2} \mathrm{SO}_{4}$ and in $1 \mathrm{M} \mathrm{KOH}$ electrolyte media. Both carbide catalysts showed strong stability in the alkaline and acidic media for over $20 \mathrm{~h}$ of operation. Thus, this work shows a viable way to synthesize nanostructured TMC-based electrocatalysts for hydrogen production.

\section{EXPERIMENTAL SECTION}

\section{Materials and Methods}

The commercial $\mathrm{Mo}_{2} \mathrm{C}$ and $\mathrm{W}_{2} \mathrm{C}$ chemicals of reagent grade were acquired from Sigma-Aldrich and were used without further purification. The following procedure was followed to prepare the chemically reduced $\mathrm{Mo}_{2} \mathrm{C}$ and $\mathrm{W}_{2} \mathrm{C}$ nanostructures (Hussain et al., 2019a). First, $2 \mathrm{~g}$ of commercial powder was well-disseminated in $100 \mathrm{~mL}$ of ethanol in a beaker to form a clear solution with the assistance of a room temperature stirring process. Subsequently, $50 \mathrm{~mL}$ of liquid ammonia solution was mixed with the black solution mixture, which was followed by a magnetic stirring at $85^{\circ} \mathrm{C}$ until the ethanol was completely evaporated from the mixture. The settled residue was then purified with de-ionized water and alcohol, sometimes using a centrifuge process, and the resultant material was placed in an 
oven at $60^{\circ} \mathrm{C}$ for $6 \mathrm{~h}$. Finally, the collected black powders were placed in a quartz tube, and their temperature was raised with a heating rate of $5^{\circ} \mathrm{C} / \mathrm{min}$ to attain $850^{\circ} \mathrm{C}$ with the support of a $\mathrm{CH}_{4} / \mathrm{Ar} / \mathrm{H}_{2}$-mixture gas flow $(50 \mathrm{sccm})$. The final chemically reduced $\mathrm{Mo}_{2} \mathrm{C}$ and $\mathrm{W}_{2} \mathrm{C}$ samples were kept in a vacuum desiccator for further analysis.

\section{Electrochemical Measurements}

The electrocatalytic HER properties were examined in an acid medium $\left(0.5 \mathrm{M} \mathrm{H}_{2} \mathrm{SO}_{4}\right.$ solution) and a alkaline medium (1 M $\mathrm{KOH}$ ) by using a typical three-electrode setup. A saturated calomel electrode (SCE) and a carbon rod were used as the reference and counter electrodes, respectively. For the preparation of a working electrode, a 10:80:10 weight ratio of poly (vinylidene fluoride), active materials $\left(\mathrm{W}_{2} \mathrm{C}\right.$ and $\left.\mathrm{Mo}_{2} \mathrm{C}\right)$, and carbon black was used with an $\mathrm{N}$-methyl-2-pyrrolidone solvent. The resultant sample was coated onto $\mathrm{NF}$ and dried overnight at $90^{\circ} \mathrm{C}$. $\mathrm{Mo}_{2} \mathrm{C}$ - and $\mathrm{W}_{2} \mathrm{C}$-loaded $\mathrm{NF}$ was employed as the working electrode. The LSV was recorded using a scan rate of $10 \mathrm{mV} \mathrm{s}^{-1}$ at room temperature. All the LSV performances were completed using SCE and then referenced to a reversible hydrogen electrode (RHE) scale using the following equation: $\mathrm{E}$ $(\mathrm{RHE})=\mathrm{E}(\mathrm{SCE})+\mathrm{E}^{\circ}(\mathrm{SCE})+0.059 \mathrm{pH}$. An electrochemical impedance spectroscopy (EIS) study was performed within the $0.1 \mathrm{~Hz}$ to $1 \mathrm{MHz}$ frequency with a perturbation voltage of $10 \mathrm{mV}$.

\section{Characterization}

$\mathrm{Mo}_{2} \mathrm{C}$ and $\mathrm{W}_{2} \mathrm{C}$ nanoparticles were studied using Raman spectroscopy (Renishaw Invia RE04, Ar laser-512 nm), FESEM (HITACHI S-4700), a Rigaku Ultima IV diffractometer with $\mathrm{Cu}-\mathrm{K} \alpha$ radiation $(0.154 \mathrm{~nm})$, JEOL-2010F TEM with the help of Gatan DM software (version 3.0), PHI 5000 Versa Probe XPS, and a 3Flex surface characterization analyzer for nitrogen adsorption and desorption measurement at $77 \mathrm{~K}$ (Micromeritics, USA).

\section{REFERENCES}

An, K., and $\mathrm{Xu}, \mathrm{X}$. (2019). $\mathrm{Mo}_{2} \mathrm{C}$ based electrocatalyst with nitrogen doped threedimensional mesoporous carbon as matrix, synthesis and HER activity study. Electrochim. Acta 293, 348-355. doi: 10.1016/j.electacta.2018.10.050

An, K., Xu, X., and Liu, X. (2017). Mo2C-based electrocatalyst with biomassderived sulfur and nitrogen co-doped carbon as a matrix for hydrogen evolution and organic pollutant removal. ACS Sustain. Chem. Eng. 6, 1446-1455. doi: 10.1021/acssuschemeng.7b03882

Ang, H., Wang, H., Li, B., Zong, Y., Wang, X., and Yan, Q. (2016). 3D hierarchical porous Mo2C for efficient hydrogen evolution. Small 12, 2859-2865. doi: 10.1002/smll.201600110

Berglund, S. P., He, H., Chemelewski, W. D., Celio, H., Dolocan, A., and Mullins, C. B. (2014). p-Si/W2C and p-Si/W2C/Pt photocathodes for the hydrogen evolution reaction. J. Am. Chem. Soc. 136, 1535-1544. doi: 10.1021/ja411604k

Bockris, J. M., and Potter, E. (1952). The mechanism of the cathodic hydrogen evolution reaction. J. Electrochem. Soc. 99, 169-186. doi: 10.1149/1.2779692

Chen, W. F., Wang, C. H., Sasaki, K., Marinkovic, N., Xu, W., Muckerman, J., et al. (2013). Highly active and durable nanostructured molybdenum carbide electrocatalysts for hydrogen production. Energy Environ. Sci. 6, 943-951. doi: $10.1039 / \mathrm{c} 2 \mathrm{ee} 23891 \mathrm{~h}$

Chen, Y. Y., Zhang, Y., Jiang, W. J., Zhang, X., Dai, Z., Wan, L. J., et al. (2016). Pomegranate-like N, P-doped Mo2C@ C nanospheres as highly active

\section{DATA AVAILABILITY STATEMENT}

All datasets generated for this study are included in the article/Supplementary Material.

\section{AUTHOR CONTRIBUTIONS}

$\mathrm{SH}$ and JJ prepared the manuscript. SH performed the material synthesis. DV and AF actively took part in the characterization of catalysts. WS and K-SA performed XPS measurement and physical characterization of synthesized materials. H-SK, S-HC, and JJ did planning, design experimental work, and discussion. JJ edited the paper.

\section{FUNDING}

This research was supported by the Basic Science Research Program through the National Research Foundation of Korea (NRF), funded by the Ministry of Education (2015M3A7B7045194, 2017R1C1B5076952, and 2016M3A7B4909942), by the MOTIE (10052928) and the KSRC (Korea Semiconductor Research Consortium) support programs for the development of future semiconductor devices. This work was supported by the Korea Institute of Energy Technology Evaluation and Planning (KETEP) and the Ministry of Trade, Industry \& Energy (MOTIE) of the Republic of Korea (20172010106080).

\section{SUPPLEMENTARY MATERIAL}

The Supplementary Material for this article can be found online at: https://www.frontiersin.org/articles/10.3389/fchem. 2019.00716/full\#supplementary-material

electrocatalysts for alkaline hydrogen evolution. ACS Nano 10, 8851-8860. doi: 10.1021/acsnano.6b04725

Chen, Z., Cummins, D., Reinecke, B. N., Clark, E., Sunkara, M. K., and Jaramillo, T. F. (2011). Core-shell $\mathrm{MoO}_{3}-\mathrm{MoS}_{2}$ nanowires for hydrogen evolution: a functional design for electrocatalytic materials. Nano Lett. 11, 4168-4175. doi: $10.1021 / \mathrm{nl} 2020476$

Colton, R. J., Huang, J. T. J., and Rabalais, J. W. (1975). Electronic structure of tungsten carbide and its catalytic behavior. Chem. Phys. Lett. 34, 337-339. doi: 10.1016/0009-2614(75)85287-0

Cui, W., Cheng, N., Liu, Q., Ge, C., Asiri, A. M., and Sun, X. (2014). Mo2C nanoparticles decorated graphitic carbon sheets: biopolymer-derived solidstate synthesis and application as an efficient electrocatalyst for hydrogen generation. ACS Catal. 4, 2658-2661. doi: 10.1021/cs5005294

Fan, M., Zheng, Y., Li, A., Ma, Y., Huo, Q., Qiao, Z. A., et al. (2018). Sprout-like growth of mesoporous Mo2C/NC nanonetworks as efficient electrocatalysts for hydrogen evolution. Chem CatChem 10, 625-631. doi: 10.1002/cctc.201701417

Fan, X., Liu, Y., Peng, Z., Zhang, Z., Zhou, H., Zhang, X., et al. (2017). Atomic $\mathrm{H}$-induced $\mathrm{Mo} 2 \mathrm{C}$ hybrid as an active and stable bifunctional electrocatalyst. ACS Nano 11, 384-394. doi: 10.1021/acsnano.6b 06089

Fei, H., Dong, J., Arellano-Jiménez, M. J., Ye, G., Dong Kim, N., Samuel, E. L. G., et al. (2015). Atomic cobalt on nitrogen-doped graphene for hydrogen generation. Nat. Commun. 6:8668. doi: 10.1038/ncomms9668 
Gao, Q., Zhao, X., Xiao, Y., Zhao, D., and Cao, M. (2014). A mild route to mesoporous Mo2C-C hybrid nanospheres for high performance lithium-ion batteries. Nanoscale 6, 6151-6157. doi: 10.1039/c3nr06678a

Gong, Q., Wang, Y., Hu, Q., Zhou, J., Feng, R., Duchesne, P. N., et al. (2016). Ultrasmall and phase-pure W 2 C nanoparticles for efficient electrocatalytic and photoelectrochemical hydrogen evolution. Nat. Commun. 7:13216. doi: $10.1038 /$ ncomms 13216

Huang, Y., Gong, Q., Song, X., Feng, K., Nie, K., Zhao, F., et al. (2016). Mo2C nanoparticles dispersed on hierarchical carbon microflowers for efficient electrocatalytic hydrogen evolution. ACS Nano 10, 11337-11343. doi: 10.1021/acsnano.6b06580

Hussain, S., Akbar, K., Vikraman, D., Afzal, R. A., Song, W., An, K. S., et al. (2018). $\mathrm{WS}_{(1-\mathrm{x})} \mathrm{Se}_{\mathrm{x}}$ nanoparticles decorated three-dimensional graphene on nickel foam: a robust and highly efficient electrocatalyst for the hydrogen evolution reaction. Nanomaterials 8:929. doi: 10.3390/nano8110929

Hussain, S., Vikraman, D., Akbar, K., Naqvi, B. A., Abbas, S. M., Kim, H. S., et al. (2019a). Fabrication of $\mathrm{MoSe}_{2}$ decorated three-dimensional graphene composites structure as a highly stable electrocatalyst for improved hydrogen evolution reaction. Renew. Energy 143, 1659-1669. doi: 10.1016/j.renene.2019.05.126

Hussain, S., Zaidi, S. A., Vikraman, D., Kim, H. S., Jung, J. (2019b). Facile preparation of molybdenum carbide $\left(\mathrm{Mo}_{2} \mathrm{C}\right)$ nanoparticles and its effective utilization in electrochemical sensing of folic acid via imprinting. Biosens. Bioelectron. 140:111330. doi: 10.1016/j.bios.2019.111330

Ishii, T., Yamada, K., Osuga, N., Imashiro, Y., and Ozaki. J. I. (2016). Single-step synthesis of W2C nanoparticle-dispersed carbon electrocatalysts for hydrogen evolution reactions utilizing phosphate groups on carbon edge sites. ACS Omega 1, 689-695. doi: 10.1021/acsomega.6b00179

Jacobsson, T. J., Fjällström, V., Sahlberg, M., Edoff, M., and Edvinsson, T. (2013). A monolithic device for solar water splitting based on series interconnected thin film absorbers reaching over 10\% solar-to-hydrogen efficiency. Energy Environ. Sci. 6, 3676-3683. doi: 10.1039/c3ee42519c

Ko, Y. J., Cho, J. M., Kim, I., Jeong, D. S., Lee, K. S., Park, J. K., et al. (2017). Tungsten carbide nanowalls as electrocatalyst for hydrogen evolution reaction: new approach to durability issue. Appl. Catal. B Environ. 203, 684-691. doi: 10.1016/j.apcatb.2016.10.085

Kou, Z., Wang, T., Cai, Y., Guan, C., Pu, Z., Zhu, C., et al. (2018). Ultrafine molybdenum carbide nanocrystals confined in carbon foams via a colloidconfinement route for efficient hydrogen production. Small Methods 2:1700396. doi: 10.1002/smtd.201700396

Kou, Z., Wang, T., Pu, Z., Wu, L., Xi, K., and Mu, S. (2019). Realizing the extraction of carbon from WC for in situ formation of W/WC heterostructures with efficient photoelectrochemical hydrogen evolution. Nanoscale Horizons 4, 196-201. doi: 10.1039/C8NH00275D

Kou, Z., Xi, K., Pu, Z., and Mu, S. (2017). Constructing carbon-cohered high-index (222) faceted tantalum carbide nanocrystals as a robust hydrogen evolution catalyst. Nano Energy 36, 374-380. doi: 10.1016/j.nanoen.2017.04.057

Laursen, A. B., Kegnæs, S., Dahl, S., and Chorkendorff, I. (2012). Molybdenum sulfides-efficient and viable materials for electro-and photoelectrocatalytic hydrogen evolution. Energy Environ. Sci. 5, 5577-5591. doi: 10.1039/c2ee0 $2618 \mathrm{j}$

Li, J. S., Wang, Y., Liu, C. H., Li, S. L., Wang, Y. G., Dong, L. Z., et al. (2016). Coupled molybdenum carbide and reduced graphene oxide electrocatalysts for efficient hydrogen evolution. Nat. Commun. 7:11204. doi: 10.1038/ncomms11204

Liang, Q., Jin, H., Wang, Z., Xiong, Y., Yuan, S., Zeng, X., et al. (2019). Metal-organic frameworks derived reverse-encapsulation Co-NC@ Mo2C complex for efficient overall water splitting. Nano Energy 57, 746-752. doi: 10.1016/j.nanoen.2018.12.060

Lin, Z., Cai, L., Lu, W., and Chai, Y. (2017). Phase and facet control of molybdenum carbide nanosheet observed by in situ TEM. Small 13:1700051. doi: 10.1002/smll.201700051

Lv, C., Huang, Z., Yang, Q., Wei, G., Chen, Z., Humphrey, M. G., et al. (2017). Ultrafast synthesis of molybdenum carbide nanoparticles for efficient hydrogen generation. J. Mater. Chem. A 5, 22805-22812. doi: 10.1039/C7TA06266D

Lv, Y., and Wang, X. (2017). Nonprecious metal phosphides as catalysts for hydrogen evolution, oxygen reduction and evolution reactions. Catal. Sci. Technol. 7, 3676-3691. doi: 10.1039/C7CY00715A
Ma, F. X., Wu, H. B., Xia, B. Y., Xu, C. Y., and Lou, X. W. (2015). Hierarchical $\beta-\mathrm{Mo}_{2} \mathrm{C}$ nanotubes organized by ultrathin nanosheets as a highly efficient electrocatalyst for hydrogen production. Angew. Chem. Int. Ed. 54, 15395-15399. doi: 10.1002/anie.201508715

Ma, L., Ting, L. R. L., Molinari, V., Giordano, C., and Yeo, B. S. (2015). Efficient hydrogen evolution reaction catalyzed by molybdenum carbide and molybdenum nitride nanocatalysts synthesized via the urea glass route. $J$. Mater. Chem. A 3, 8361-8368. doi: 10.1039/C5TA00139K

Ma, R., Zhou, Y., Chen, Y., Li, P., Liu, Q., and Wang, J. (2015). Ultrafine molybdenum carbide nanoparticles composited with carbon as a highly active hydrogen-evolution electrocatalyst. Angew. Chem. 127, 14936-14940. doi: 10.1002/ange.201506727

Neylon, M., Choi, S., Kwon, H., Curry, K., and Thompson, L. (1999). Catalytic properties of early transition metal nitrides and carbides: n-butane hydrogenolysis, dehydrogenation and isomerization. Appl. Catal. A Gen. 183, 253-263. doi: 10.1016/S0926-860X(99)00053-8

Ojha, K., Saha, S., Kolev, H., Kumar, B., and Ganguli, A. K. (2016). Composites of graphene-Mo2C rods: highly active and stable electrocatalyst for hydrogen evolution reaction. Electrochim. Acta 193, 268-274. doi: 10.1016/j.electacta.2016.02.081

Pan, L. F., Li, Y. H., Yang, S., Liu, P. F., Yu, M. Q., and Yang, H. G. (2014). Molybdenum carbide stabilized on graphene with high electrocatalytic activity for hydrogen evolution reaction. Chem. Commun. 50, 13135-13137. doi: 10.1039/C4CC05698A

Pei, Y., Cheng, Y., Chen, J., Smith, W., Dong, P., Ajayan, P. M., et al. (2018). Recent developments of transition metal phosphides as catalysts in the energy conversion field. J. Mater. Chem. A 6, 23220-23243. doi: 10.1039/C8TA09454C

Peng, L., Nie, Y., Zhang, L., Xiang, R., Wang, J., Chen, H., et al. (2017). Selfassembly-and preshaping-assisted synthesis of molybdenum carbide supported on ultrathin nitrogen-doped graphitic carbon lamellas for the hydrogen evolution reaction. Chem CatChem 9, 1588-1593. doi: 10.1002/cctc.201700239

Peng, S., Li, L., Han, X., Sun, W., Srinivasan, M., Mhaisalkar, S. G., et al. (2014). Cobalt sulfide nanosheet/graphene/carbon nanotube nanocomposites as flexible electrodes for hydrogen evolution. Angew. Chem. 126, 12802-12807. doi: 10.1002/ange.201408876

Pu, Z., Wang, M., Kou, Z., Amiinu, I. S., and Mu, S. (2016). Mo 2 C quantum dot embedded chitosan-derived nitrogen-doped carbon for efficient hydrogen evolution in a broad $\mathrm{pH}$ range. Chem. Commun. 52, 12753-12756. doi: 10.1039/C6CC06267A

Ren, X., Wei, Q., Ren, P., Wang, Y., and Chen, R. (2018). Synthesis of flower-like $\mathrm{MoSe}_{2} @ \mathrm{MoS}_{2}$ nanocomposites as the high efficient water splitting electrocatalyst. Mater. Lett. 231, 213-216. doi: 10.1016/j.matlet.2018.08.049

Seok, J., Lee, J. H., Cho, S., Ji, B., Kim, H. W., Kwon, M., et al. (2017). Active hydrogen evolution through lattice distortion in metallic MoTe2, 2D. Materials 4:025061. doi: 10.1088/2053-1583/aa659d

Shi, Z., Nie, K., Shao, Z. J., Gao, B., Lin, H., Zhang, H., et al. (2017). PhosphorusMo2C@carbon nanowires toward efficient electrochemical hydrogen evolution: composition, structural and electronic regulation. Energy Environ. Sci. 10, 1262-1271. doi: 10.1039/C7EE00388A

Tang, C., Sun, A., Xu, Y., Wu, Z., and Wang, D. (2015). High specific surface area Mo2C nanoparticles as an efficient electrocatalyst for hydrogen evolution. J. Power Sour. 296, 18-22. doi: 10.1016/j.jpowsour.2015.07.016

Vikraman, D., Akbar, K., Hussain, S., Yoo, G., Jang, J. Y., Chun, S. H., et al. (2017). Direct synthesis of thickness-tunable $\mathrm{MoS}_{2}$ quantum dot thin layers: optical, structural and electrical properties and their application to hydrogen evolution. Nano Energy 35, 101-114. doi: 10.1016/j.nanoen.2017.03.031

Vikraman, D., Hussain, S., Akbar, K., Karuppasamy, K., Chun, S. H., Jung, J., et al. (2019a). Design of basal plane edges in metal-doped nanostripes-structured $\mathrm{MoSe}_{2}$ atomic layers to enhance hydrogen evolution reaction activity. ACS Sustain. Chem. Eng. 7, 458-469. doi: 10.1021/acssuschemeng.8b03921

Vikraman, D., Hussain, S., Akbar, K., Truong, L., Kathalingam, A., S.-,Chun, H., et al. (2018). Improved hydrogen evolution reaction performance using $\mathrm{MoS}_{2}$ $\mathrm{WS}_{2}$ heterostructures by physicochemical process. ACS Sustain. Chem. Eng. 6, 8400-8409. doi: 10.1021/acssuschemeng.8b00524

Vikraman, D., Hussain, S., Truong, L., Karuppasamy, K., Kim, H. J., Maiyalagan, T., et al. (2019b). Fabrication of $\mathrm{MoS}_{2} / \mathrm{WSe} e_{2}$ heterostructures as electrocatalyst for enhanced hydrogen evolution reaction. Appl. Surf. Sci. 480, 611-620. doi: 10.1016/j.apsusc.2019.02.236 
Vrubel, H., and Hu, X. (2012). Molybdenum boride and carbide catalyze hydrogen evolution in both acidic and basic solutions. Angew. Chem. 124, 12875-12878. doi: 10.1002/ange.2012

Wan, C., Regmi, Y. N., and Leonard, B. M. (2014). Multiple phases of molybdenum carbide as electrocatalysts for the hydrogen evolution reaction. Angew. Chem. 126, 6525-6528. doi: 10.1002/ange.201402998

Wang, D., Guo, T., and Wu, Z. (2018). Hierarchical Mo2C/C scaffolds organized by nanosheets as highly efficient electrocatalysts for hydrogen production. ACS Sustain. Chem. Eng. 6, 13995-14003. doi: 10.1021/acssuschemeng.8b 02469

Wang, D., Wang, J., Luo, X., Wu, Z., and Ye, L. (2017). In situ preparation of $\mathrm{Mo} 2 \mathrm{C}$ nanoparticles embedded in ketjenblack carbon as highly efficient electrocatalysts for hydrogen evolution. ACS Sustai. Chem. Eng. 6, 983-990. doi: 10.1021/acssuschemeng.7b03317

Wu, H. B., Xia, B. Y., Yu, L., Yu, X. Y., and Lou, X. W. D. (2015). Porous molybdenum carbide nano-octahedrons synthesized via confined carburization in metal-organic frameworks for efficient hydrogen production. Nat. Commun. 6:6512. doi: 10.1038/ncomms7512

Wu, Z. Y., Hu, B. C., Wu, P., Liang, H. W., Yu, Z. L., Lin, Y., et al. (2016). $\mathrm{Mo}_{2} \mathrm{C}$ nanoparticles embedded within bacterial cellulose-derived 3D N-doped carbon nanofiber networks for efficient hydrogen evolution. NPG Asia Mater. 8:e288. doi: 10.1038/am.2016.87

Yan, G., Wu, C., Tan, H., Feng, X., Yan, L., Zang, H., et al. (2017). NCarbon coated P-W2C composite as efficient electrocatalyst for hydrogen evolution reactions over the whole $\mathrm{pH}$ range. J. Mater. Chem. A 5, 765-772. doi: 10.1039/C6TA09052D

Youn, D. H., Han, S., Kim, J. Y., Kim, J. Y., Park, H., Choi, S. H., et al. (2014). Highly active and stable hydrogen evolution electrocatalysts based on molybdenum compounds on carbon nanotube-graphene hybrid support. ACS Nano 8, 5164-5173. doi: 10.1021/nn5012144

Yu, F., Gao, Y., Lang, Z., Ma, Y., Yin, L., Du, J., et al. (2018). Electrocatalytic performance of ultrasmall Mo $2 \mathrm{C}$ affected by different transition metal dopants in hydrogen evolution reaction. Nanoscale 10, 6080-6087. doi: 10.1039/C8NR00908B

Yuan, W., Huang, Q., Yang, X., Cui, Z., Zhu, S., Li, Z., et al. (2018). Twodimensional lamellar Mo2C for electrochemical hydrogen production: insights into the origin of HER activity in acid and alkaline electrolytes. ACS Appl. Mater. Interfaces 10, 40500-40508. doi: 10.1021/acsami.8b13215

Zhang, L. N., Ma, Y. Y., Lang, Z. L., Wang, Y. H., Khan, S. U., Yan, G., et al. (2018) Ultrafine cable-like WC/W $2 \mathrm{C}$ heterojunction nanowires covered by graphitic carbon towards highly efficient electrocatalytic hydrogen evolution. J. Mater. Chem. A 6, 15395-15403. doi: 10.1039/C8TA05007D

Zhang, R., Wang, X., Yu, S., Wen, T., Zhu, X., Yang, F., et al. (2017). Ternary NiCo2Px nanowires as $\mathrm{pH}$-universal electrocatalysts for highly efficient hydrogen evolution reaction. Adv. Mater. 29:1605502. doi: 10.1002/adma.201605502

Zhou, H., Yu, F., Huang, Y., Sun, J., Zhu, Z., Nielsen, R. J., et al. (2016). Efficient hydrogen evolution by ternary molybdenum sulfoselenide particles on self-standing porous nickel diselenide foam. Nat. Commun. 7:12765. doi: $10.1038 /$ ncomms 12765

Zhu, J., Lu, X., and Wang, L. (2016). Synthesis of a $\mathrm{MoO}_{3} / \mathrm{Ti}_{3} \mathrm{C}_{2} \mathrm{~T}_{\mathrm{x}}$ composite with enhanced capacitive performance for supercapacitors. RSC Adv. 6, 98506-98513. doi: 10.1039/C6RA15651G

Conflict of Interest: The authors declare that the research was conducted in the absence of any commercial or financial relationships that could be construed as a potential conflict of interest.

Copyright (c) 2019 Hussain, Vikraman, Feroze, Song, An, Kim, Chun and Jung. This is an open-access article distributed under the terms of the Creative Commons Attribution License (CC BY). The use, distribution or reproduction in other forums is permitted, provided the original author(s) and the copyright owner(s) are credited and that the original publication in this journal is cited, in accordance with accepted academic practice. No use, distribution or reproduction is permitted which does not comply with these terms. 